\title{
Simple strengthening techniques for Non-Engineered buildings against seismic actions
}

\author{
Marina Traykova \\ University of Architecture, Civil Engineering and Geodesy, Sofia, Bulgaria
}

Christos Giarlelis

Equidas Consulting Engineers, Greece

Andreas Lampropoulos

School of Environment and Technology, University of Brighton, UK

Stephanos Dritsos

Department of Civil Engineering, University of Patras, Greece

Jon Moseley

Consulting Engineer, Greece

Contact: marina5261@abv.bg

\begin{abstract}
It is estimated that non-engineered construction accounts for more than half of the buildings in most of the cities of the developing world. These buildings account for most of the collapses and fatalities during earthquakes. To address this problem, the possible solutions are either to limit their construction in highly seismic zones or strengthen the existing ones. Lack of integrity of a building's structural elements, improper detailing of a building's structural elements and low quality of construction materials are typical problems found in many of these structures due to misconceptions, lack of guidelines and skilled technicians. In this work, some of the most popular strengthening techniques for non-engineered buildings based on different case studies from various countries are presented. General conclusions and recommendations, which may serve as guidelines for future rehabilitation works, are drawn.
\end{abstract}

Keywords: Non-engineered buildings, seismic upgrade, seismic strengthening.

\section{Introduction}

Non-engineered (NE) buildings are those that have been spontaneously and informally constructed in various countries without any or with little intervention by qualified architects and engineers in their design and supervision [1]. NE buildings are constructed from locally available materials including field stone, fired brick, concrete blocks, adobe or rammed earth, wood and, in certain cases, even with reinforced concrete. These types of buildings are prevalent in rural areas of countries with a high seismic risk such as Turkey, Iran, Afghanistan, Pakistan, India, Nepal and China, as well as countries in Latin America. As a result, they account for most of the collapses and fatalities during earthquakes since, usually, no measures have been taken against earthquakes 
due to either a lack of knowledge or economic considerations. The high seismic vulnerability of these structures has been demonstrated in various earthquakes that have affected countries of the developing world including the recent disastrous 2010 Haiti and 2015 Nepal earthquakes.

For the majority of these buildings, their replacement with new, non-seismic prone ones is not a practical option due to the high cost. However, in many cases, seismic strengthening with simple techniques could be a viable option. In many countries, the seismic building code for NE structures is either not available or is not obligatory.

This paper presents the most popular strengthening techniques for NE buildings based on different case studies from various countries. It is part of the work of IABSE Working Group 7, Earthquake Resistant Structures, which has one its aims to minimize the vulnerability and improve the seismic resistance of NE structures.

\section{Vulnerability of NE buildings}

\subsection{Structural vulnerability}

Structural vulnerability is related to the seismic behaviour of the NE buildings. There are a number of factors that define the structural response:

\subsubsection{Location of the structure}

The geographic location determines the type and extent of the expected hazard such as liquefaction, earthquake-induced landslide or tsunami run off. A building located on soft soil, or over a liquefiable sandy stratum, is likely to be more vulnerable than one located on firm soil. In addition, the proximity to a fault may be crucial, as a near fault structure is subjected to intense pulse type input accelerations.

\subsubsection{Behaviour of adjacent buildings}

Pounding may be a crucial factor in building failure. A well designed and constructed building may be affected adversely by the behaviour of an adjacent vulnerable building. The existence of a structural joint between two adjacent buildings results in avoiding pounding. On the other hand, it should be noted that in certain cases weak structures may benefit from their contact to stronger ones. It should also be noted that there is ongoing research on the seismic interaction of buildings in a block (without seismic joints), since it has been observed that corner structures usually sustain more damage.

\subsubsection{Number of storeys}

In the absence of any control over the design and quality of construction in developing countries, the seismic vulnerability of a building usually increases with its height.

\subsubsection{Shape (configuration)}

Complex shapes (e.g., L-shape, Y shape, H-shape, etc.) increase a building's vulnerability to damage and possible collapse during an earthquake. A basic reason for that is the torsional character of the response of such buildings.

Large offsets in plan and elevation lead to unequal distribution of stiffness/torsion effects. Re-entrant angles create an excessive concentration of stresses during an earthquake, as opposed to solid circular, square or triangular layouts, which are the most efficient. Regarding rectangular layouts, this is less efficient especially if it is elongated with a length to width ratio over 3 to 1 . In this case structural joints should be provided.

Asymmetrical buildings are more vulnerable to damage during an earthquake than buildings symmetrical in plan (in both directions) as well as in elevation.

\subsubsection{Age of buildings}

NE constructions have a limited life span, which is on average about 30 years. Many of theses structures last much longer. However, their vulnerability increases with age due to material deterioration.

\subsubsection{Construction typology}

Brick masonry, stone masonry, adobe, timber, cement-block masonry and concrete frame are the principal types of building construction in cities in the developing countries. When 
considering seismic vulnerability, the type of building and the structural materials employed form a key factor.

\subsubsection{Modifications or additions}

NE modifications or additions to an original NE structure frequently decrease further the structural capacity. Modifications usually include more openings in walls or even the removal of parts of inner walls, which decreases the strength of the affected structural elements. Additions may be in elevation or in plan. The former is a practice that appears to be rampant in developing countries. Sometimes the structure can barely support its self-weight. Additions in plan may result to complex building shapes or to structures with different seismic behaviour (due to the use of different structural systems) being connected.

\subsubsection{Maintenance}

A poorly maintained building becomes gradually vulnerable. Material deterioration due to aging or weather conditions is inevitable and, usually, measures to address this problem are not taken due to lack of knowledge or cost.

\subsection{Non-structural vulnerability}

Non-structural elements of a building include ceilings, windows, doors, non-structural partition walls, as well as electrical, mechanical, plumbing equipment and installations. A building may survive an earthquake but be inhabitable due to damage to its non-structural elements. Moreover, the non-structural elements could also lead to structural damage to the building or cause injuries to the occupants.

It is estimated that the cost of the damage to nonstructural elements in residential buildings is about $30 \%$ of the total cost, which rises much higher in offices and critical facilities and may be even more than that of the structural elements. This is especially true for hospitals, where $85 \%$ to $90 \%$ of their cost lies in the architectural parts, the mechanical and electrical systems and in the medical equipment.

\subsection{Functional vulnerability}

Functional vulnerability needs also to be considered and minimised or eliminated especially for critical facilities such as hospitals, emergency operation theatres, communication centres, etc. It is crucial that the services provided by these facilities remain uninterrupted to meet the demands of the communities at the time when these are most needed.

\section{Typical damage in NE buildings}

\subsection{Masonry buildings}

Poor tensile strength of masonry buildings is the primary cause of different types of observed damage during earthquakes.

The seismic vulnerable features of masonry buildings include: Weak wall junctions (loss of box action), lack of integrity between load-bearing elements, lack of a diaphragm, long unsupported walls (behaving as cantilever walls), delamination of walls (reduction in load carrying capacity), large and unsymmetrical openings (lack of lateral load resisting elements and torsion effects) and softstorey effects. Sequences of failure and occurrence of damage types suggest that the factors that govern damage are: (a) Corners are more likely to fail than mid-wall elements, (b) Any panel between two corner failures is unrestrained and is unlikely to remain standing, (c) Non-load bearing panels are more likely to fail than load bearing, (d) Elements generally fail progressively and (e) The failure of one element increases the probability of failure of neighbouring elements. Figure 1 depicts some of these failures.

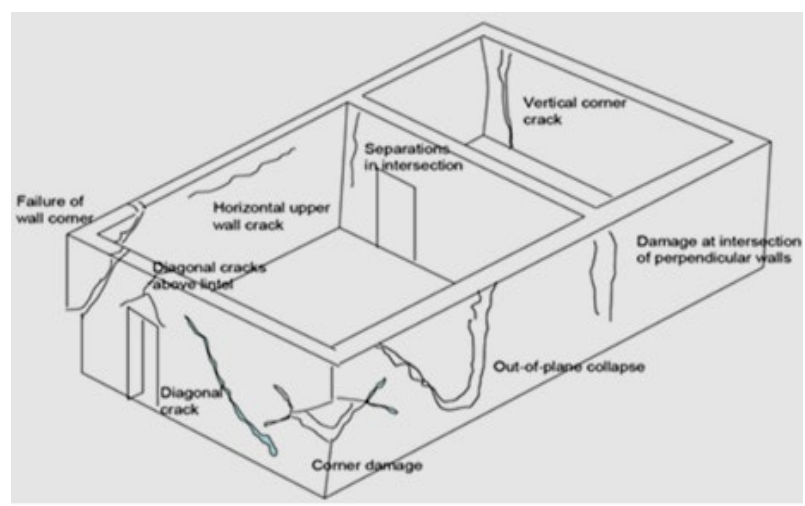

Figure 1. Typical damage in masonry structures

\subsection{Earthen buildings}

Adobe buildings are highly vulnerable to seismic 
forces. Their vertical and lateral load-resisting system is earthen walls, which have a very low resistance to out-of-plane forces. The loads from the roof (usually comprising of timber or bamboo with a mud layer) are transferred to the walls (adobe block masonry or earthen) and then to the foundations, so a good connection between these three parts is crucial. However, this is not usually the case.

Typical types of damage to adobe construction can be summarised by the following: (a) Rocking of independent structural parts and in-plane diagonal and horizontal shear cracks, (b) Shear cracks due to pounding between orthogonal walls, (c) Pediment overturning in gable-end walls, (d) Gable-end wall overturning and possible toe crushing at their base, (e) Diagonal shear cracks in transversal walls. Gable-end wall overturning with portions of transversal walls, (f) Shear failure and sliding of peripheral bracing, (g) Diagonal tensile cracks from out-of-plane bending and diagonal shear cracks in transversal walls, (h) Separation and overturning of small wall segments, (i) Separation and overturning of large wall segments, (j) In plane shear cracks near openings
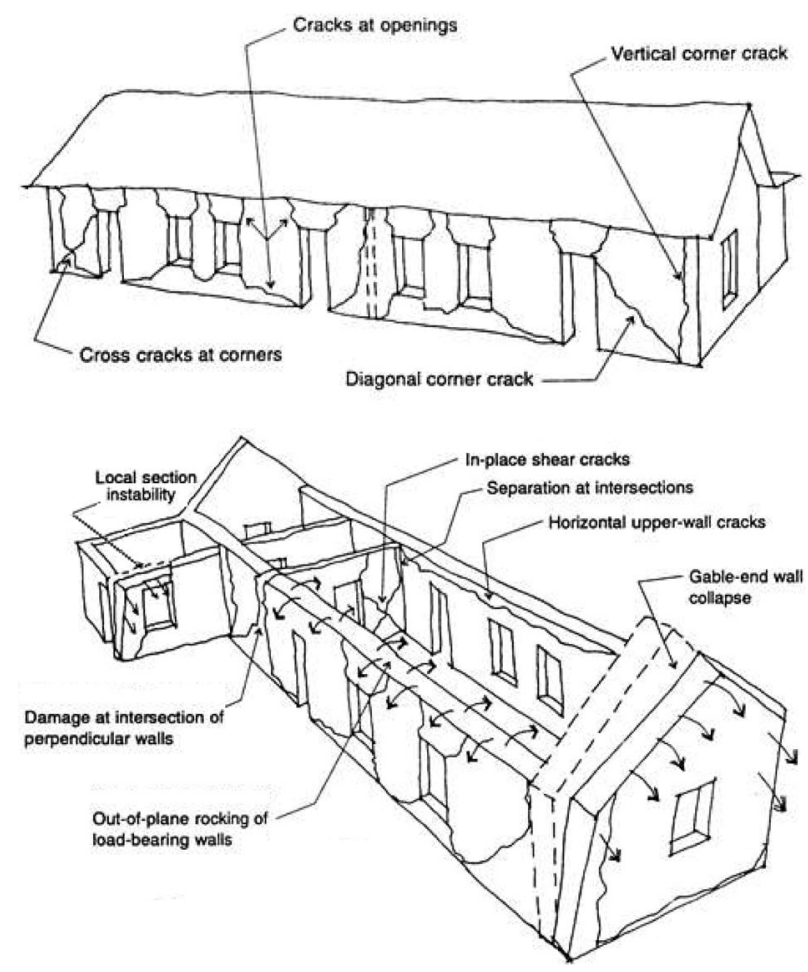

Figure 2. Typical damage in earthen (adobe) structures [2] and masonry piers, (k) Corner dislocation and overturning and (l) Partial disintegration and loss of structural material. Figure 2 presents some of these failures.

\subsection{Reinforced concrete buildings}

NE reinforced concrete structures usually suffer from low quality materials (concrete and steel), inadequate cross sections, inadequate reinforcement or detailing that leads to shear failure, flexural failure or joint failure. Serious flaws in the structural system are very common and include short columns, soft storeys and insufficient lateral capacity. In addition, these structures have low ductility due to inadequate detailing of reinforcement, quality of steel or even structural configuration, so failure may lead to total collapse without time for the residents to escape. The weight of these structures may further increase human losses.

\subsection{Timber buildings}

Structures made from timber frames with infill masonry or timber cladding (such as Himis and Bagdadi buildings) are considered less seismically vulnerable, since the lateral resisting system can perform well in tension and it is relatively ductile. However, a good connection between timber elements and an adequate foundation are essential in order to ensure a good seismic performance.

\section{Simple strengthening techniques for NE buildings against seismic actions}

The variety of NE buildings is so extended that it is very difficult to cover all the specific problems in one document, guidelines or codes. However, eliminating the structural vulnerabilities presented earlier in this paper is related to: (a) The development of a good architectural layout concerning the geometry in plan and in elevation (see also section 2.1.4 above) (b) Increased ductility and robustness (c) Avoiding stress concentrations at the corners of the openings (d) Avoiding weak wall-to-wall or wall-to-roof connections (e) Avoiding soft storeys (f) Creation of strong diaphragms and (g) Adequate foundations. 
The same suggestions of good practice can be used in order to improve the performance of existing NE buildings along with a variety of strengthening techniques. Regarding the latter, some of the more widely used methods are presented in the following selected case studies.

The most popular materials for strengthening are: bamboo, reeds, cane, crushed cane, vines, rope, timber, wire, steel bars, etc. The techniques for strengthening could be summarised by: Reduction of mass, addition of new walls, introduction of beams, adding horizontal diaphragm action, strengthening of corner and wall intersections and an adequate layout.

The following case studies present real examples of strengthening of NE buildings in different countries and provide valuable knowledge of the application of various techniques.

\subsection{Case study 1 - School complex in Indonesia}

The structural assessment of an elementary school located in the city of Bandung, West Java consisting of two buildings [3] concluded that strengthening was required. Both buildings consist of weak RC frames with masonry infill walls.

Two types of retrofitting strategies were adopted, depending on the structural capacity of the structures: (a) For the weakest structure, the strengthening approach was to add adequate RC frames on mat footings, as shown in Figure 3, and proper detailing of the connections of structural elements and (b) For the stronger building, the retrofit consisted of applying wire mesh to the infill wall elements and increasing the structural capacity of the foundation through the implementation of double tie beams next to the existing ones (Figure 4). For both structures, proper detailing was applied to the roof truss systems.

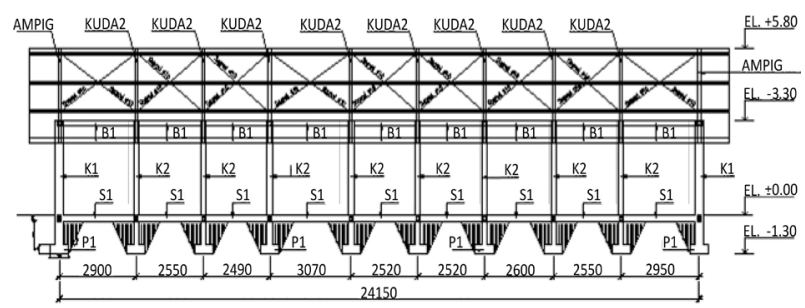

Figure 3. Implementation of new RC frames at a school building in Indonesia [3]

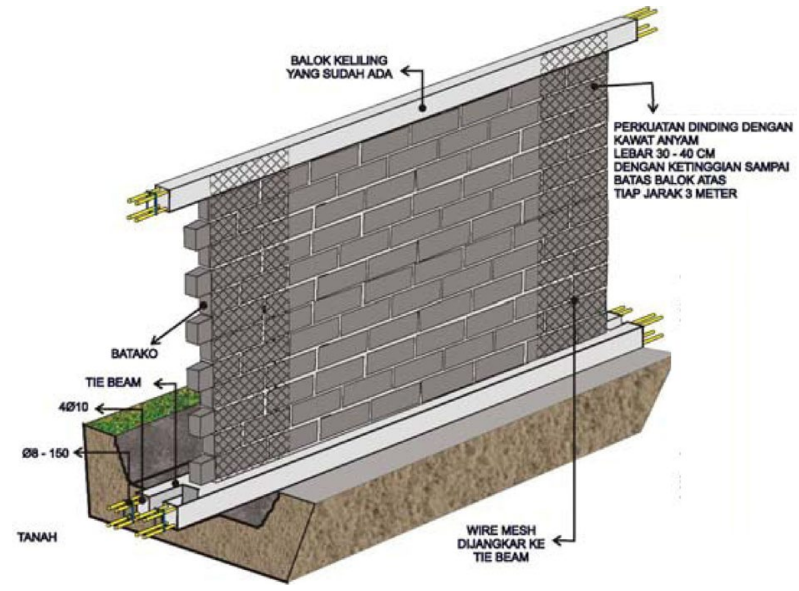

Figure 4. Strengthening of masonry infills at a school building in Indonesia [3]

\subsection{Case study 2 - Experience after the Haiti earthquake}

A large number of buildings in Haiti [4] have a structural system consisting of relatively small dimensioned reinforced concrete frame elements with hollow concrete block (HCB) infills. During the 2010 Haiti earthquake, the most frequent cause of structural collapse appeared to be the development of soft storey mechanisms.

The suggested reconstruction method was to place horizontal and vertical reinforcement in the HCB walls and to use superior masonry units and mortar mixes. This method was selected as the primary approach for repairing failed $\mathrm{HCB}$ due to its good earthquake performance, reduced cost and also because it used local resources including materials, contractors and personnel that can be found at the local level. In addition, the placement of reinforcement in the walls increases the building ductility without modifying the dynamic behaviour. To date, more than 5000 buildings have been retrofitted using this approach.

\subsection{Case study 3 - Seismic strengthening techniques in Bangladesh}

In Bangladesh, a large number of NE buildings are constructed using sun-dried earthen blocks (mud house) as the structural material [5]. This type of structure is very vulnerable to earthquakes due to the brittle nature of the material used and the lack of a lateral force resisting system.

For the improvement of a mud house (Figure 5), 
wooden bracing may be used along with metal straps at the connections. However, a good and low cost technique is the insertion of bamboo poles at the inner and outer side of the walls. A concrete plinth may fix the bamboo at the ground level. Then, holes are made through the walls to connect the bamboo poles at the inner and outer sides of the walls using bamboo splints and wire. At the top of the wall, these bamboo poles would be connected using the half bamboo splints in a truss pattern. This provides a lateral force resisting system.

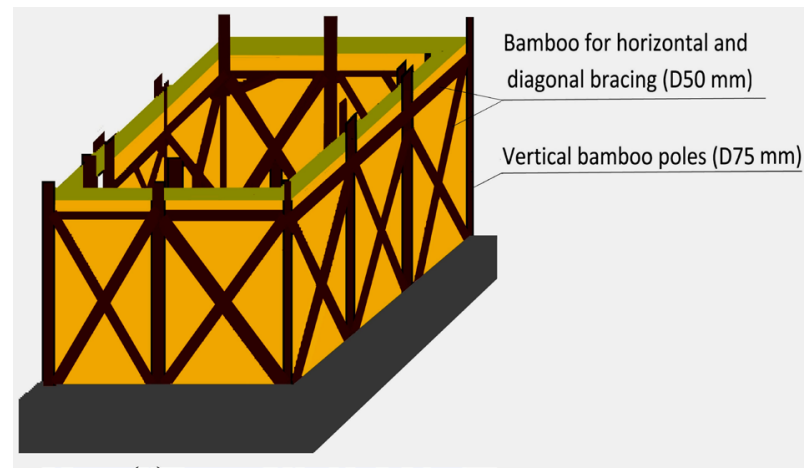

Figure 5. Strengthening of mud houses, [5]

It should be mentioned that various experiments show that the tensile strength of bamboo is approximately one third of that of high strength steel and bonding bamboo with mortar is good enough to be used as reinforcement in masonry. Its low cost makes the construction affordable for the communities in the area.

\subsection{Case study 4 - Seismic strengthening techniques in Nepal}

Most buildings in Nepal are made of stone and are not engineered since there is no process for Building Code enforcement in rural areas. Therefore, the damage from the 2015 Nepal earthquake was extensive. Simple strengthening techniques (Figure 6) that were suggested [6] comprise of: (a) Roof/floor retrofit with anchorage to walls thus creating diaphragms, (b) Insertion of bond stones in walls, bandages at different levels and splints at critical sections and (c) For timber frames, the creation of bracing (knee bracing, diagonal bracing) in order to strengthen beamcolumn connections and improving the anchorage of timber columns to the foundation.

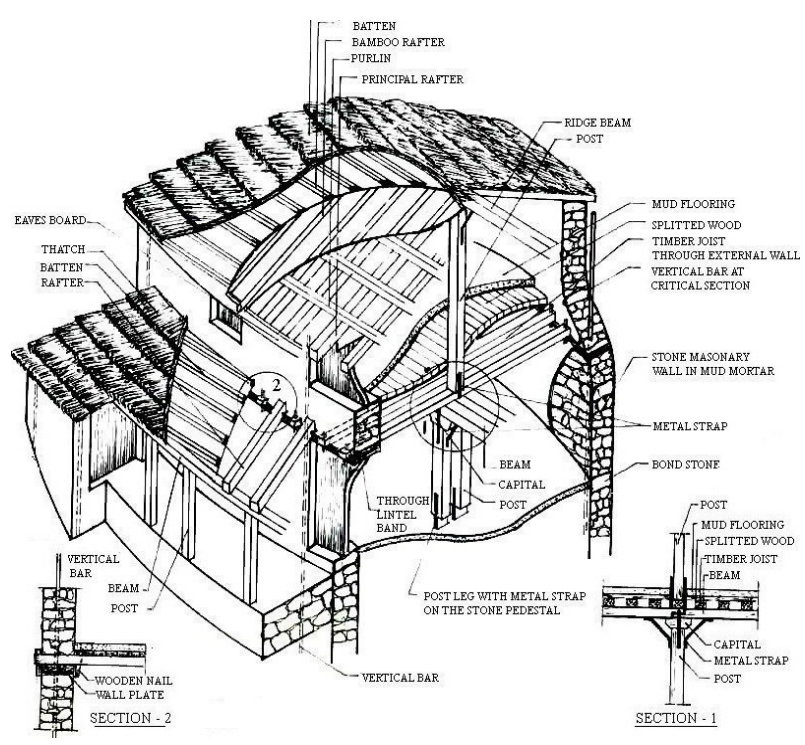

Figure 6. Illustration of simple strengthening techniques in Nepal [6]

\subsection{Case study 5 - Strengthening of rural buildings in Kashmir}

\subsubsection{Sultan Daki High School at Uri Block}

The Sultan Daki High School at Uri Block [7] is a complex comprising of 6 buildings. One of the buildings suffered damage during the devastating 2005 Kashmir earthquake. The buildings are characteristic examples of the rural architecture of the area, with masonry walls made of stone and timber roofs. There are a large number of window openings, which decreases the stiffness and the shear strength of the structures.

The strengthening (Figure 7) included: Installing
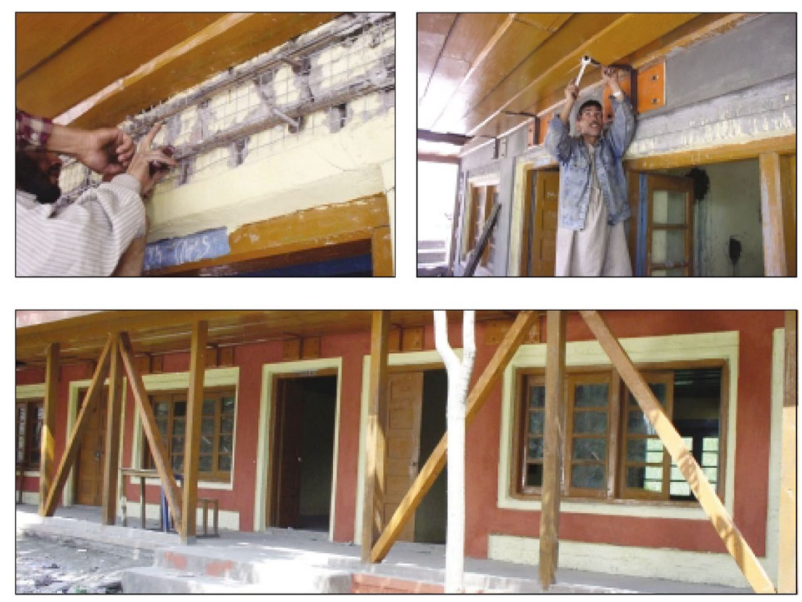

Figure 7. Strengthening with belts, roof anchoring and diagonal timber bracing [7] 
vertical reinforcement at inside corners, anchoring the roof which, amongst other things, enforces diaphragm action at the roof level, in-plane bracing at the attic floor level (to reinforce the diaphragm), installing wire mesh to the walls creating reinforced belts on both sides, diagonal timber bracing on the perimeter and encasement of windows with reinforced vertical and horizontal belts.

\subsubsection{Sub-District Hospital at Kupawada}

This is an important medical facility since it covers a large catchment area. An assessment study concluded that the structure was of high risk due to a large number of window openings along with an increased floor height in certain areas.

The strengthening of the hospital (Figure 8) consisted of installing vertical reinforcement in the corners, in-plane bracing at the attic floor level, anchoring the roof truss and placing encasement around openings.

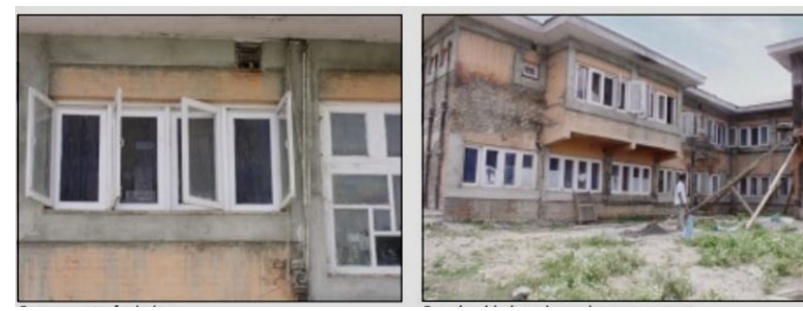

Figure 8. Strengthening with belt encasement around openings [7]

\subsection{Case study 6 - The Church of Kuno Tambo and the Ica Cathedral (Peru)}

The Church of Kuño Tambo, a religious adobe structure of the $17^{\text {th }}$ century, is located in the Cusco region of Peru. It is a historical structure, representative of the churches built in the Andes during the Spanish Viceroyalty. The structure was in a bad condition due to earthquakes in addition to settlement, humidity and lack of maintenance.

The strengthening technique that was applied [8] involved placing a combination of buttresses and bracing elements (i.e. corner keys, horizontal keys, bond beams and anchored tie beams). The reestablishment or the addition of buttresses (Figure 9) can efficiently address low or compromised out-of-plane capacity and minimise

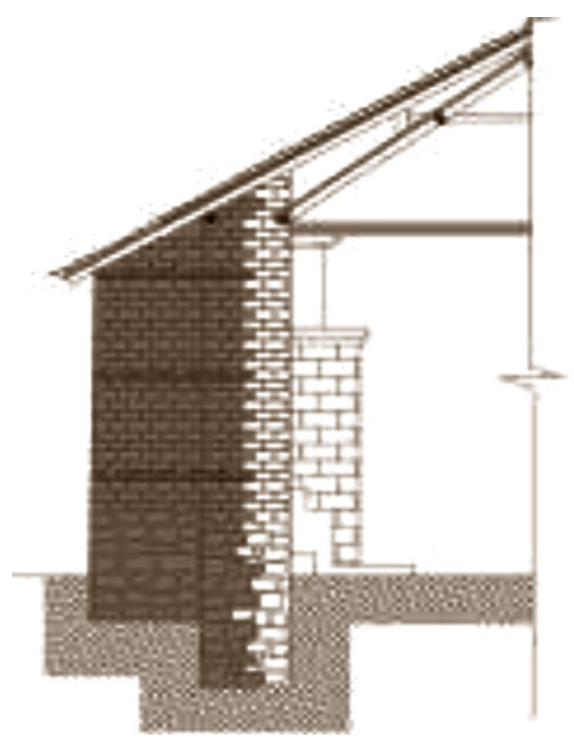

Figure 9. Church of Kuno Tambo, Peru, cross section of new buttress [8]

lateral deflections, especially in walls of large spans.

Connectivity between the existing earthen walls and the new buttresses can be ensured by inserting horizontal timber elements at various heights. To ensure connectivity and substantial stiffness in corners between orthogonal walls and pillars, orthogonal or diagonal timber keys should be used. The insertion should be made in horizontal planes at various elevations and involve mostly the upper parts of the walls. For existing cracks, several processes that respect the historic fabric can be applicable, such as partial replacement of material, stitching, repointing and grout injections with mud based grouts. Furthermore, additional lateral restraint can be offered by the means of tie beams. This system is placed at the level of the top eaves, embedded across the entire thickness of the walls. It can be subjected to both axial tension and compression, given the dynamic character of seismic loads. Thus, for the system of ties to work both in tension and compression, an adequate anchoring system is needed. A double system of vertical timber anchors, attached close to the interior and exterior surfaces of each wall can be very effective. Finally, the implementation of an internal horizontal timber frame system, at the top level and through the entire thickness of the earthen walls can enhance substantially increase the capacity under lateral forces. 


\section{Conclusions and recommendations}

The high seismic vulnerability of non-engineered structures has been demonstrated in various earthquakes that have struck countries of the developing world. In this paper, some of the most popular strengthening techniques for nonengineered buildings based on different case studies have been presented. Despite the fact that these examples come from different countries and that non-engineered building types may be different, similarities can be recognised in the retrofitting approach. The reason for this is that the weaknesses of various classes of NE buildings are similar.

In developing countries, an international and national partnership would be the correct way to perform inspection and reconstruction. The following actions are recommended to improve the situation:

A repair programme should emphasise the use of local resources including materials, contractors and personnel.

Since in many countries non-engineered construction is inevitable for the time being, emphasis should be placed on the development of simple guidelines which should be distributed widely to home owners, builders and craftsmen.

Community awareness should be improved by appropriate programmes and campaigns.

Strengthening programmes should be launched for public facilities and funding should be available to communities and individuals.

Quality control or inspection is needed from the local authority to identify the buildings of high risk.

\section{References}

[1] Arya A.S., Boen T., Ishiyama Y. Guidelines for earthquake resistant non-engineered construction. UNESCO, Paris; 2014.

[2] Tolles E.L., Webster F., Crosby A., Kimbro E. Survey of damage to historic adobe buildings after the January 24 Northridge earthquake. Getty Conservation Institute Scientific Program Report, J. Paul Getty
Trust Publication, Los Angeles, CA; 1996.

[3] Kusumastuti D., Pribadi K.S., Rildova R. Reducing earthquake vulnerability of NE buildings: Case study of retrofitting of school building in Indonesia. $14^{\text {th }}$ WCEE, 2008, Beijing, China; 2008.

[4] Mallick D., Dritsos S., Sonda D. Construction and strengthening of non-engineered buildings in developing seismic-prone countries. Structural Engineering International. 2013; 23(2), p. 225-228.

[5] Alam M.J., Ahsan R., Akhter F., Pual A. Earthquake resistant NE building construction for rural area in Bangladesh; c2014 [cited 2018 February 10]. Available from: http://www.iitk.ac.in/nicee/wcee/arti cle/14_09-02-0006.PDF

[6] Parajuli Y.K., Bothara J.K., Upadhyay B.K. Traditional oval-shaped rural stone house in Nepal. World Housing Encyclopedia Report 47; 2002.

[7] Desai R., Desai R. Manual for restoration and retrofitting of rural structures in Kashmir, how to reduce vulnerability of existing structures in earthquake affected areas of Jammu and Kashmir. UNESCOUNDP, India, IN/2007/CL/18; 2007.

[8] Lourenco P., Torrealva D., Cancino C., Wong K., Karanikoloudis G., Ciocci M. Innovative traditional technologies for rehabilitation and protection of earthen structures: The Getty Conservation Institute seismic retrofitting project. $3^{\text {rd }}$ International Conference on Protection of Historical Constructions. Lisbon, Portugal, July; 2017. 